\title{
Hubungan Keberadaan Kontak Serumah dan Perilaku Ibu terhadap Kejadian Tuberkulosis Anak
}

\section{Relationship between The Existence of Household Contacts and Maternal Behavior towards Incidence of Childhood Tuberculosis}

\author{
Dyah Wulan Sumekar Rengganis Wardani ${ }^{*}$, Ari Rosmala Dewi², \\ Suharmanto ${ }^{1}$ \\ 1 Bagian Ilmu Kedokteran Komunitas dan Kesehatan Masyarakat, Fakultas \\ Kedokteran Universitas Lampung, Indonesia \\ ${ }^{2}$ Dinas Kesehatan Kota Metro, Lampung, Indonesia \\ *Korespondensi penulis: dyah.wulan@fk.unila.ac.id
}

Penyerahan: 21-08-2020, Perbaikan: 31-08-2020, Diterima: 22-09-2010

\begin{abstract}
Factors that increase the risk of transmission to children were the presence of household contact and lack of knowledge of the mother. However, there were not many studies that presented it to children in Bandar Lampung. Bandar Lampung had an increased incidence of TB from year to year and thus to be a potential source of TB transmission to children. This study aimed to analyze the relationship between household contact and maternal behavior towards the incidence of childhood TB in five community health centers in Bandar Lampung, where childhood TB was. This study was a case-control study with a case sample of 66 children with TB and a control sample of 66 children who did not suffer from TB. The variables in the study included household contact (presence of contact, the intensity of contact, and engagement of the relationship) and mother's behavior (mother's knowledge and BCG immunization). Data were collected through interviews with questionnaire tools followed by Chi-Square analysis. The results showed a relationship between the presence of contact, contact intensity, engagement of relationship, knowledge and BCG immunization, and incidence of childhood TB. The results were expected can be used to show variables that need to be intervened, which then can reduce the incidence of childhood TB.
\end{abstract}

Keywords: Presence of household contacts, Maternal behavior, Childhood tuberculosis.

\section{ABSTRAK}

Salah satu faktor yang meningkatkan risiko penularan pada anak adalah terdapatnya kontak serumah dan kurangnya pengetahuan ibu, akan tetapi belum banyak penelitian yang mengkaji hubungan variabel-variabel tersebut terhadap penularan kepada anak di Bandar Lampung. Bandar Lampung memiliki angka kejadian TB yang meningkat dari tahun ke tahun dan berpotensi menjadi sumber penularan kepada anak. Penelitian ini bertujuan untuk menganalisis hubungan keberadaan kontak serumah dan perilaku ibu terhadap kejadian TB anak di lima puskesmas di Bandar Lampung yang terdapat kasus TB anak. Penelitian ini adalah penelitian case control dengan sampel kasus sebanyak 66 anak penderita TB dan sampel kontrol sebanyak 66 anak yang tidak menderita TB. Variabel pada penelitian mencakup kontak serumah (keberadaan kontak, intensitas kontak dan kedekatan hubungan) serta perilaku ibu (pengetahuan ibu dan imunisasi BCG). Data dikumpulkan melalui wawancara dengan alat bantu kuesioner yang dilanjutkan dengan analisis Chi Square. Hasil penelitian menunjukkan bahwa terdapat hubungan keberadaan kontak, intensitas kontak, kedekatan hubungan, pengetahuan serta imunisasi BCG 
terhadap kejadian TB anak. Hasil penelitian ini diharapkan dapat dimanfaatkan untuk menunjukkan variabel yang perlu diintervensi yang pada akhirnya dapat menurunkan kejadian TB anak.

Kata kunci: Keberadaan kontak serumah, Perilaku ibu, Tuberkulosis anak.

\section{PENDAHULUAN}

Dampak tuberkulosis (TB) sebagai kedaruratan global telah ditetapkan oleh World Health Organization (WHO) sejak tahun 1993. Namun secara umum penyakit ini hanya dievaluasi pada populasi dewasa. Tuberkulosis pada anak menjadi aspek yang kurang mendapat perhatian pada epidemi TB yang terjadi saat ini. Diperkirakan satu juta anak menderita TB dan 233.000 anak meninggal karena TB pada tahun 2017. Namun, beban aktual TB pada anak-anak kemungkinan lebih tinggi mengingat tantangan dalam mendiagnosa TB anak yang cukup sulit. Lebih lanjut, anak-anak dapat terkena penyakit TB pada usia berapapun, tetapi paling umum, di negara endemis TB, antara $1-4$ tahun (World Health Organization, 2018). Di Indonesia proporsi kasus TB anak secara keseluruhan pada tahun 2017 mengalami peningkatan yaitu sebesar 8,5 \% (52.929 anak) dibandingkan tahun 2011 yang hanya sebesar $0,7 \%$ (World Health Organization, 2018).

Anak yang terinfeksi Mycobacterium tuberculosis memiliki risiko yang lebih besar untuk berkembang menjadi TB aktif. $\mathrm{Hal}$ ini mengindikasikan bahwa TB cenderung mengancam tumbuh kembang anak dibandingkan TB remaja maupun dewasa yang umumnya telah memiliki sistem imunitas yang lebih baik (Upe, 2017). Dimensi penularan TB secara umum pada anak adalah sebagai dampak dari kontak orang TB dewasa dengan
BTA positif yang rentan menularkan ke anak terlebih apabila kontak secara intensif (Amanullah et al., 2014). Selain itu, kejadian TB pada anak juga dipengaruhi oleh perilaku ibu, terutama dalam pencegahan penularan TB ( Upe, 2017; Lönnroth et al., 2010; Rasanathan et al., 2011).

Kota Bandar Lampung merupakan salah satu kabupaten/ kota tertinggi pertama dalam hal penemuan kasus TB di Provinsi Lampung Tahun 2018. Berdasarkan data Dinas Kesehatan (Dinkes) Kota Bandar Lampung Tahun 2018, ditemukan 3.759 orang penderita TB dengan pasien BTA positif sebanyak 1.646 kasus. Banyaknya kasus TB dengan BTA positif yang cukup banyak mengindikasikan banyaknya sumber penular yang cukup berbahaya terutama bagi anak-anak. Lebih jauh, kasus TB anak di Kota Bandar Lampung yang tercatat pada tahun 2018 terdapat 359 kasus, yang mengalami peningkatan dibandingkan tahun 2017 yang hanya sebesar 225 kasus TB anak (Dinas Kesehatan Kota Bandar Lampung, 2018).

Berdasarkan latar belakang tersebut, maka penelitian ini bertujuan untuk menganalisis besar risiko keberadaan kontak serumah dan perilaku ibu terhadap kejadian TB anak. Penelitian tersebut belum banyak dilakukan di Bandar Lampung. Di sisi lain, pengetahuan tersebut sangat bermanfaat bagi program penanggulangan TB anak, khususnya dalam mendukung kebijakan dan 
intervensi dalam menurunkan insiden TB anak.

\section{METODE}

Penelitian ini merupakan penelitian case control yang bertujuan untuk mengukur besar risiko variabel keberadaan kontak serumah dan perilaku ibu terhadap kejadian TB anak. Penelitian ini dilakukan di puskesmas di Kota Bandar Lampung yang terdapat penderita TB anak, yaitu Puskesmas Kedaton, Way Halim, Simpur, Gedong Air dan Way Kandis Kota Bandar Lampung.

Populasi penelitian mencakup populasi kasus dan populasi kontrol. Populasi kasus adalah seluruh penderita TB anak yang tercatat di Puskesmas Kedaton, Way Halim, Simpur, Gedong Air dan Way Kandis dengan alamat lengkap pada Oktober 2018-Februari 2019. Sedangkan populasi kontrol adalah pasien yang berkunjung ke poli anak di puskesmas studi yang tidak menderita TB. Sampel pada kelompok kasus dan kelompok kontrol adalah populasi yang bersedia. Sampel minimal untuk kelompok kasus dan kelompok kontrol masing-masing adalah 66 anak. Teknik pengambilan sampel adalah dengan menggunakan proporsional random sampling.

Variabel penelitian pada penelitian ini terdiri dari variabel independen dan dependen. Variabel dependen terdiri dari kejadian TB anak (ya, tidak), sedangkan variabel independen terdiri dari: keberadaan kontak serumah (ya, tidak), intensitas kontak ( $\geq 8$ jam, $<8$ jam), kedekatan hubungan (ada hubungan genetik ayah/ibu, famili dekat: nenek, kakek, saudara, tidak ada hubungan genetik), pengetahuan ibu (rendah, tinggi), imunisasi Bacillus CalmetteGuerin (BCG) (tidak, ya).
Pengumpulan data dilakukan dengan cara pengambilan data primer dan data sekunder. Data sekunder mencakup data penderita TB anak dan bukan penderita TB anak yang diperoleh dari Puskesmas Kedaton, Way Halim, Simpur, Gedong Air dan Way Kandis Kota Bandar Lampung. Sedangkan data primer mencakup data keberadaan kontak serumah dan perilaku ibu yang dilakukan melalui wawancara kepada responden. Pengumpulan data dilakukan dengan wawancara terhadap responden (ibu /pengasuh anak) untuk mendapatkan data sesuai dengan kuesioner yang telah dipersiapkan. Analisis data bivariat dengan Chi Square dilakukan untuk menganalisis hubungan antar variabel. Penelitian ini juga telah mendapatkan persetujuan etik dari Fakultas Kedokteran Universitas Lampung

783/UN26.18/PP.05.02.00/2019.

\section{HASIL}

Merujuk pada tabel 1 dapat diketahui bahwa pada anak yang menderita TB lebih banyak terdapat kontak serumah, lebih banyak intensitas kontak dengan penderita TB yaitu $<8$ jam atau kadang-kadang serta lebih banyak kontak penderita TB merupakan hubungan genetik baik ayah ibu atau kakek nenek. Sedangkan pada anak yang tidak menderita TB, semuanya tidak terdapat keberadaan kontak serumah. Lebih lanjut pada analisis bivariat juga diperoleh nilai $p$ kurang dari 0,001 yang berarti terdapat hubungan antara keberadaan kontak serumah, intensitas kontak dan kedekatan hubungan terhadap kejadian TB anak.

Tabel 1 juga menunjukkan bahwa pada anak yang menderita TB juga lebih banyak terdapat pada ibu dengan pengetahuan kurang - 
sedang serta tidak memberikan imunisasi BCG pada anaknya. Sedangkan pada anak yang tidak menderita TB, lebih banyak merupakan anak dengan ibu yang mempunyai pengetahuan baik dan melakukan imunisasi BCG pada anaknya. Hasil analisis bivariat juga menunjukkan terdapat hubungan antara pengetahuan ibu dan imunisasi BCG.

Tabel 1. Hubungan Antar Variabel

\begin{tabular}{|c|c|c|c|}
\hline \multirow[t]{2}{*}{ Variabel } & \multicolumn{2}{|c|}{ TB pada Anak } & \multirow[t]{2}{*}{ p-value } \\
\hline & Ya & Tidak & \\
\hline \multicolumn{4}{|l|}{ Keberadaan kontak serumah } \\
\hline Ada & $36(100 \%)$ & $0(0 \%)$ & \multirow{2}{*}{$<0.001$} \\
\hline Tidak ada & $37(33.6 \%)$ & $73(66.4 \%)$ & \\
\hline \multicolumn{4}{|l|}{ Intensitas kontak } \\
\hline >8 jam & $12(100 \%)$ & $0(0 \%)$ & \multirow{3}{*}{$<0.001$} \\
\hline Kadang-kadang & $22(100 \%)$ & $0(0 \%)$ & \\
\hline$<8$ jam & $39(34.8 \%)$ & $73(65.2 \%)$ & \\
\hline \multicolumn{4}{|l|}{ Kedekatan hubungan } \\
\hline Ada hubungan genetik (ayah, ibu) & $23(100 \%)$ & $0(0 \%)$ & \multirow{3}{*}{$<0.001$} \\
\hline Famili dekat (kakek, nenek) & $19(100 \%)$ & $0(0 \%)$ & \\
\hline Tidak ada & $31(29.8 \%)$ & $73(70.2 \%)$ & \\
\hline \multicolumn{4}{|l|}{ Pengetahuan ibu } \\
\hline Kurang & $2(100 \%)$ & $0(0 \%)$ & \multirow{3}{*}{0.005} \\
\hline Sedang & $8(100 \%)$ & $0(0 \%)$ & \\
\hline Baik & $63(46.3 \%)$ & $73(53.7 \%)$ & \\
\hline \multicolumn{4}{|l|}{ Imunisasi BCG } \\
\hline Tidak & $26(100 \%)$ & $0(0 \%)$ & \multirow{3}{*}{$<0.001$} \\
\hline Imunisasi tetapi tidak ada scar & $36(83.7 \%)$ & $7(16.3 \%)$ & \\
\hline Imunisasi dan ada scar & $11(14.3 \%)$ & $66(85.7 \%)$ & \\
\hline
\end{tabular}

\section{PEMBAHASAN}

Penelitian ini menunjukkan terdapat hubungan antara kontak serumah, kedekatan hubungan dan intensitas kontak terhadap kejadian TB anak. Hasil penelitian ini sesuai dengan penelitian yang dilakukan di Bandar Lampung, Indonesia, penelitian di Lima, Peru dan penelitian di Pakistan yang mendapatkan hasil bahwa keberadaan kontak serumah akan meningkatkan risiko tertular TB pada anggota keluarga yang lain (Wardani \& Wahono, 2018; Grandjean et al., 2011; Khan et al., 2014). Hasil penelitian ini sesuai dengan penelitian yang dilakukan di Indonesia yang menyatakan bahwa tingginya prevalensi TB pada anak sebagian besar terjadi pada anak yang pernah mengalami kontak atau tinggal bersama dengan penderita TB BTA positif dewasa. Pada penelitian tersebut keberadaan kontak serumah akan meningkatkan risiko anak untuk menderita TB anak 3,91 kali lebih besar dibandingkan anak yang tidak mempunyai riwayat kontak. Keberadaan kontak dapat berupa kontak serumah (orang yang saat ini tinggal bersama ataupun pernah tinggal bersama selama satu malam 
atau lebih pada satu tempat tinggal) serta kontak di sekitar rumah/ tetangga (Upe, 2017). Tuberkulosis ditularkan melalui percikan droplet penderita pada waktu batuk atau bersin. Dengan terdapatnya kontak serumah, maka di dalam rumah akan terdapat paparan droplet penderita TB yang meningkatkan risiko anak untuk terpapar TB (Kementrian Kesehatan RI, 2016).

Hasil penelitian ini juga sesuai dengan penelitian yang menyatakan bahwa penularan TB salah satunya dipengaruhi oleh seberapa lama orang kontak dengan penderita lain (Kartasasmita, 2009). Kontak jangka panjang dengan penderita TB menyebabkan risiko tertular penyakit lebih besar dibandingkan orang yang tidak ada kontak jangka panjang (Nurwitasari, 2015). Hasil penelitian ini juga sesuai dengan review yang menyebutkan bahwa semakin erat kontak seorang anak dengan sumber penularan, semakin tinggi peluang anak tersebut mengalami infeksi TB. Kontak erat dengan pasien TB dewasa dapat dilihat dari 2 aspek yaitu aspek jarak seperti menggunakan kriteria "satu tempat tidur" dan aspek waktu "intensitas waktu </ > 8 jam/hari" (Diani, Darmawan, \& Nurhanzah, 2010). Semakin lama intensitas kontak antara anak dengan penderita TB, maka semakin banyak paparan droplet penderita TB yang akan terhirup oleh anak yang akan meningkatkan risiko anak untuk terpapar TB (Kementrian Kesehatan RI, 2016).

Hasil penelitian ini juga sesuai dengan penelitian yang menyatakan bahwa risiko tertular TB meningkat seiring dengan meningkatnya kedekatan hubungan genetik antara anak dengan penderita. Semakin erat hubungan dengan sumber penularan yang berada dalam satu rumah, semakin besar pula kemungkinan anak tersebut terpajan droplet yang infeksius (Nurwitasari, 2015; Kementrian Kesehatan RI, 2016).

Hasil penelitian ini juga menunjukkan bahwa terdapat hubungan antara pengetahuan ibu terhadap kejadian TB anak. Hasil penelitian ini sesuai dengan penelitian yang dilakukan di Bandar Lampung yang mendapatkan hasil bahwa kurangnya pengetahuan penderita TB mengakibatkan konversi sputum yang tertunda dan juga meningkatkan risiko penularan terhadap anggota keluarga (Wardani \& Wahono, 2019). Hasil penelitian ini juga sejalan dengan review yang menyatakan bahwa pendidikan dan pengetahuan yang baik akan meningkatkan indikator determinan sosial yang lain, termasuk di dalamnya akses terhadap informasi kesehatan (Braveman et al., 2011). Lebih lanjut, hasil penelitian juga mendapatkan bahwa terdapat hubungan antara pemberian imunisasi BCG terhadap kejadian TB anak. Vaksin BCG hanya diberikan satu kali saja dan memiliki daya perlindungan yang panjang, maka keterlambatan dari jadwal pemberian imunisasi yang sudah disepakati akan mengakibatkan meningkatnya risiko tertular penyakit yang tidak diinginkan. Oleh karenanya WHO dan International Union Against TB and Lung Disease (IUALTD) merekomendasikan pemberian BCG pada semua bayi (dengan pengecualian bayi dengan AIDS), terutama pada negara-negara dengan prevalensi tuberkulosis tinggi. Pemberian imunisasi BCG sebaiknya dilakukan saat bayi lahir hingga usia 2 bulan (Kementrian Kesehatan RI, 2016).

\section{KESIMPULAN}

Penelitian ini menunjukkan bahwa terdapat hubungan antara 
keberadaan kontak serumah, intensitas kontak yang tinggi, terdapatnya hubungan genetik pada kontak, pengetahuan ibu yang kurang serta tidak memberikan imunisasi BCG terhadap kejadian TB anak.

\section{SARAN}

Berdasarkan hasil penelitian di atas, perlu dilakukan peningkatan pengetahuan tentang pencegahan penularan TB pada keluarga yang memiliki kontak serumah dan anakanak yang tinggal bersama dalam satu rumah, untuk menurunkan risiko penularan TB pada anak akibat penularan dari kontak serumah.

\section{DAFTAR PUSTAKA}

Amanullah, F., Ashfaq, M., Khowaja, S., Parekh, A., Salahuddin, N., Lotia-Farrukh, I., et al. (2014). High tuberculosis prevalence in children exposed at home to drug-resistant tuberculosis, Int. J. Tuberc. Lung Dis.18(5):520527.

Braveman PA, Egerter SA, Mockenhaupt RE. (2011). Broadening the Focus: The Need to Address the Social Determinants of Health. Am. J. Prev. Med. 40:S4-18.

Diani. Darmawan. Nurhanzah. (2010). Proporsi Infeksi Tuberkulosis dan Gambaran Faktor Resiko Pada Balita Yang tinggal Dalam Satu Rumah Dengan Pasien Tuberkulosis Dewasa. Jurnal Sari Pediatri. 13(1).

Dinas Kesehatan Kota Bandar Lampung. (2018). Laporan Pencegahan dan Pemberantasan (P2) Penyakit Tuberkulosis Tahun 2018. Dinas Kesehatan Kota Bandar Lampung. Bandar Lampung.

Grandjean L, Crossa A, Gilman RH,
Herrera C, Bonilla C, Jave O, et al. (2011). Tuberculosis in Household Contacts of Multidrug-Resistant. Int. J. Tuberc. Lung Dis.15:1164-9.

Kartasasmita, C. B. (2009). Epidemiologi Tuberkulosis. Jurnal Sari Pediatri. 11(2):124129.

Kementrian Kesehatan RI. (2016). Petunjuk Teknis Manajemen dan Tatalaksana TB Anak, Dirjen P2P. Jakarta.

Khan T, Ahmed Z, Zafar M, Nisar N, Qayyum S, Shafi K. (2014). Active case finding of sputum positive pulmonary tuberculosis in household contacts of tuberculosis patients in Karachi , Pakistan. J. Assoc. Chest Physicians. 2(1):25-31.

Lönnroth, K, Castro, K. G., Chakaya, J. M., Chauhan, L. S., Floyd, K., Glaziou, P., \& Raviglione, M. C. (2010). Tuberculosis Control and Elimination 2010 - 50: Cure, Care, and Social Development. The Lancet, 375(9728), 18141829.

Nurwitasari, A. Wahyuni, C.U. (2015). Pengaruh Status Gizi dan Riwayat Kontak Terhadap Kejadian Tuberkulosis Anak di Kabupaten Jember. Jurnal Berkala Epidemiologi. 3(2):158-169.

Rasanathan, K., Sivasankara Kurup, A., Jaramillo, E., \& Lönnroth, K. (2011). The Social Determinants of Health: Key to Global Tuberculosis Control. The International Journal of Tuberculosis and Lung Disease, 15(6), S30-6.

Upe, A. Eryando, T. Purwantyastuti. Junadi, P. Clark, C. Teinjingen, E.V. (2017). Level Of Exposure to Childhood Tuberculosis in Household Contacts with Adult Pulmonary Tuberculosis. National 
Public Health Journal. 12(1):1-6.

Wardani D, Wahono E. (2018).

Prediction Model of Tuberculosis Transmission Based on Its Risk

Factors and Socioeconomic Position in Indonesia. Indian $\mathrm{J}$.

Community Med. 43(3):204-8.

Wardani D, Wahono E. (2019).

Predominant Determinants of Delayed Tuberculosis Sputum Conversion in Indonesia. Indian J. Community Med.44(1):53-7. World Health Organization. (2018). Global Tuberculosis Report. World Health Organization. Geneva. 